\title{
A Study of the Sequential Michael Addition-Ring Closure Reaction of Ethyl Acetoacetate with Chalcone: Influence of Quaternary Ammonium Cations as Phase Transfer Catalysts
}

\author{
Regina C. V. Lopes, Maria da Conceição F. de Oliveira, Telma L. G. de Lemos and \\ Marcos C. de Mattos* \\ Departamento de Química Orgânica e Inorgânica, Universidade Federal do Ceará, CP 6044, \\ 60455-970 Fortaleza - CE, Brazil
}

\begin{abstract}
A adição de Michael entre o acetoacetato de etila $\mathbf{1}$ e a chalcona $\mathbf{2}$, sob condições de Catálise de Transferência de Fase Sólido/Líquido (CTF-SL), sem solvente, produziu o aduto de Michael $\mathbf{3}$ e o composto cíclico $\mathbf{4}$, com bom rendimento. O composto 4 foi obtido majoritariamente via um processo de anelação do aduto de Michael 3. A proporção de $\mathbf{4}$ na razão 3/4 foi dependente da estrutura do cátion de amônio quaternário. Os resultados foram interpretados com base na organofilicidade e acessibilidade dos catalisadores e invocando-se um estado de transição cíclico de 6 membros, para a formação de 4, associado ao grau de quelação com $\mathrm{Q}^{+}$.
\end{abstract}

The Michael addition of ethyl acetoacetate $\mathbf{1}$ to chalcone $\mathbf{2}$ under Solid/Liquid Phase Transfer Catalysis (SL-PTC), solvent free, afforded Michael adduct $\mathbf{3}$ and an annulated compound $\mathbf{4}$ in good yield. The cyclic compound $\mathbf{4}$ was obtained in the majority via an annulation process of the Michael adduct $\mathbf{3}$. The proportion of $\mathbf{4}$ in the ratio of $\mathbf{3 / 4}$ was dependant on the structure of the quaternary ammonium cation. The results were interpreted on the basis of the organophilicity and accessibility of the catalysts as well as by invoking a 6-membered ring transition state for the formation of $\mathbf{4}$ due to the chelation level with $\mathrm{Q}^{+}$.

Keywords: Phase Transfer Catalysis, annulation, Michael reaction

\section{Introduction}

Annulation, derived from the Latin word annulatus (ringed) means "the formation of ring". In organic chemistry this term is used to describe the process of building a ring onto a pre-existing system, cyclic or noncyclic. The added ring may be of any size, although 5 - and 6-membered rings are most commonly formed. This broad definition includes in a general sense many reactions that are not normally thought of as annulation reactions, such as Diels-Alder reactions, acid-catalyzed polyolefinic ciclizations, photochemical, radical, and thermal cyclizations. The methods of annulation have proved themselves to be invaluable aids to synthetic chemists in the syntheses of such complex natural products as steroids, terpenes, and alkaloids. ${ }^{1}$

The Michael reaction, the addition of a stabilized carbon nucleophile to an eletrophilic $\mathrm{C}=\mathrm{C}$ bond, is a classical reaction for very good reasons. It is a carboncarbon and a carbon-heteroatom bond-forming reaction;

*e-mail: mcdmatto@ufc.br it is catalyzed by a large number of acids, bases, and transition metals; it is completely atom-economical; most of the functionalities of the starting materials are preserved in the products; the starting materials are readily available or are easily prepared. For these reasons, both the intermolecular and intramolecular variants of the Michael reaction are very prominent among methods used for preparing ring systems found in a wide variety of natural products. ${ }^{2}$ Stereochemical and mechanistic aspects of this classical reaction have been the object of intense investigation, mainly focused on the direct addition of enolates or stabilized carbanions. ${ }^{3}$ Regio-, enantio- and diastereoselectivity of the phase transfer catalyzed version of this type of reaction is well documented. ${ }^{4}$

\section{Results and Discussion}

Herein, we wish to report a study of the influence of the quaternary ammonium cation structure on the annulation process which occurs in the Michael addition of ethyl acetoacetate (donor) 1 to chalcone (acceptor) 2 under Solid/Liquid Phase Transfer Catalysis (SL-PTC), solvent free. This reaction afforded Michael adduct 3 and an 
annulation product $\mathbf{4}$, the later formed via intramolecular cyclization of the Michael adduct 3, Scheme 1.

The present report is divided into two parts: the first part deals with variation of the reaction parameters, to optimize product yield, 3 plus $\mathbf{4}$; the second is dedicated to a study of the influence of catalyst structure in the 6-membered annulation reaction by analyzing the ratio of $\mathbf{3 / 4}$.

\section{Part one: optimization of reaction conditions}

1,4-Addition of 1 to chalcone 2. In order to evaluate the influence of the addition of a quaternary ammonium salt, the ratio of donor/acceptor and the temperature on the rate of reaction, ethyl acetoacetate $\mathbf{1}$ was reacted with chalcone 2 , at $60{ }^{\circ} \mathrm{C}$ or room temperature, ratio of donor/ acceptor $6: 1$ or $1: 1$, solvent free, in the presence or absence of triethylbenzylammonium chloride (TEBAC) and using catalytic amount of $\mathrm{KOH}$ as base (Table 1).

A detailed monitoring of the catalyzed reaction demonstrated that no more than 15 min were necessary to afford 3 plus 4 in $98 \%$ yield (Table 1, entry 4). In addition, equal stoichiometric amounts of donor/acceptor proved to be sufficient to obtain the products in $99 \%$ global yield (Table 1, entry 7). It should be mentioned that when the reaction was conducted in the absence of catalyst at $60{ }^{\circ} \mathrm{C}$ or in presence of catalyst, but at room temperature, the products $\mathbf{3}$ plus $\mathbf{4}$ were obtained in poor yields, 38 and 33\%, respectively (Table 1 , entries 6 and 8 ). Thus, a temperature of $60{ }^{\circ} \mathrm{C}, 15 \mathrm{~min}$ of reaction time, ratio of donor/acceptor 1:1 and TEBAC as catalyst proved to be the optimum conditions to obtain $\mathbf{3}$ plus $\mathbf{4}$ in $99 \%$ global yield.
Stereochemistry of $\mathbf{3}$ and $\mathbf{4}$. The optimized reaction of $\mathbf{1}$ to chalcone afforded compound $\mathbf{3}$ as a diastereoisomeric mixture (d.e. $70 \%$ ), which we did not managed to separate by column chromatography. The relative stereochemistry of the major isomer 3a was inferred based on the analysis of the ${ }^{1} \mathrm{H}$ NMR spectra of $\mathbf{4}$, as it was obtained by an intramolecular ciclization of $\mathbf{3 a}$. The coupling constant of $12.0 \mathrm{~Hz}$ obtained for the hydrogens of the two stereogenic centers of 4 suggested for both an antiperiplanar relationship. Thus, the diastereoisomers $\mathbf{3 a}$ and $\mathbf{3 b}$ show anti and syn relative configuration, respectively (Scheme 1). It should be mentioned that compound $\mathbf{4}$ was isolated as single diasteroisomer. To the best of our knowledge, there is no report in the literature about diastereoisomeric ratio as well as relative stereochemistry discussion of the aforementioned compounds.

Part two: study of the influence of catalyst on the ratio 3/4

During the monitoring of the Michael addition of $\mathbf{1}$ to chalcone $\mathbf{2}$, we observed that the cyclic product $\mathbf{4}$ was formed in greater quantity in comparison to Michael adduct $\mathbf{3}$ (Table 1, entries 1-7). Moreover, it was possible to observe that the proportion of $\mathbf{4}$ in the ratio of $\mathbf{3 / 4}$ depends on the temperature (Table 1, entries 7 and 8), ratio of donor/acceptor (Table 1, entries 4 and 7) and presence of catalyst (Table 1, entries 4 and 6), as well as a combination of the aforementioned parameters. In order to account for these results, each reaction condition was separately analyzed.

Presence of catalyst. Scheme 2 illustrates the role the catalyst plays in the reaction.

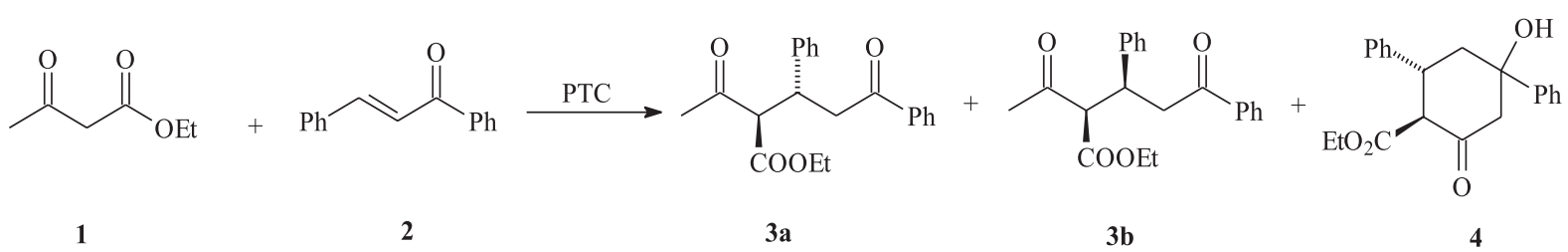

Scheme 1.

Table 1. Michael addition of $\mathbf{1}$ to chalcone $\mathbf{2}$

\begin{tabular}{|c|c|c|c|c|c|c|}
\hline Entry & Ratio of donor:acceptor & Reaction time (min) & Temperature $\left({ }^{\circ} \mathrm{C}\right)$ & Catalyst & Ratio of 3:4 & Total yield ${ }^{\mathrm{b}}$ \\
\hline 1 & $6: 1$ & 120 & 60 & TEBAC $^{\mathrm{a}}$ & $1: 4.0$ & 86 \\
\hline 2 & $6: 1$ & 240 & 60 & TEBAC & $1: 4.5$ & 89 \\
\hline 3 & $6: 1$ & 60 & 60 & TEBAC & $1: 4.0$ & 97 \\
\hline 4 & $6: 1$ & 15 & 60 & TEBAC & $1: 3.0$ & 98 \\
\hline 5 & $6: 1$ & 15 & r.t. & TEBAC & $1: 2.0$ & 86 \\
\hline 6 & $6: 1$ & 15 & 60 & none & $1: 8.5$ & 38 \\
\hline 7 & $1: 1$ & 15 & 60 & TEBAC & $1: 9.0$ & 99 \\
\hline 8 & $1: 1$ & 15 & r.t. & TEBAC & $1: 1.0$ & 33 \\
\hline
\end{tabular}

${ }^{a}$ triethylbenzylammonium chloride; bisolated product. 


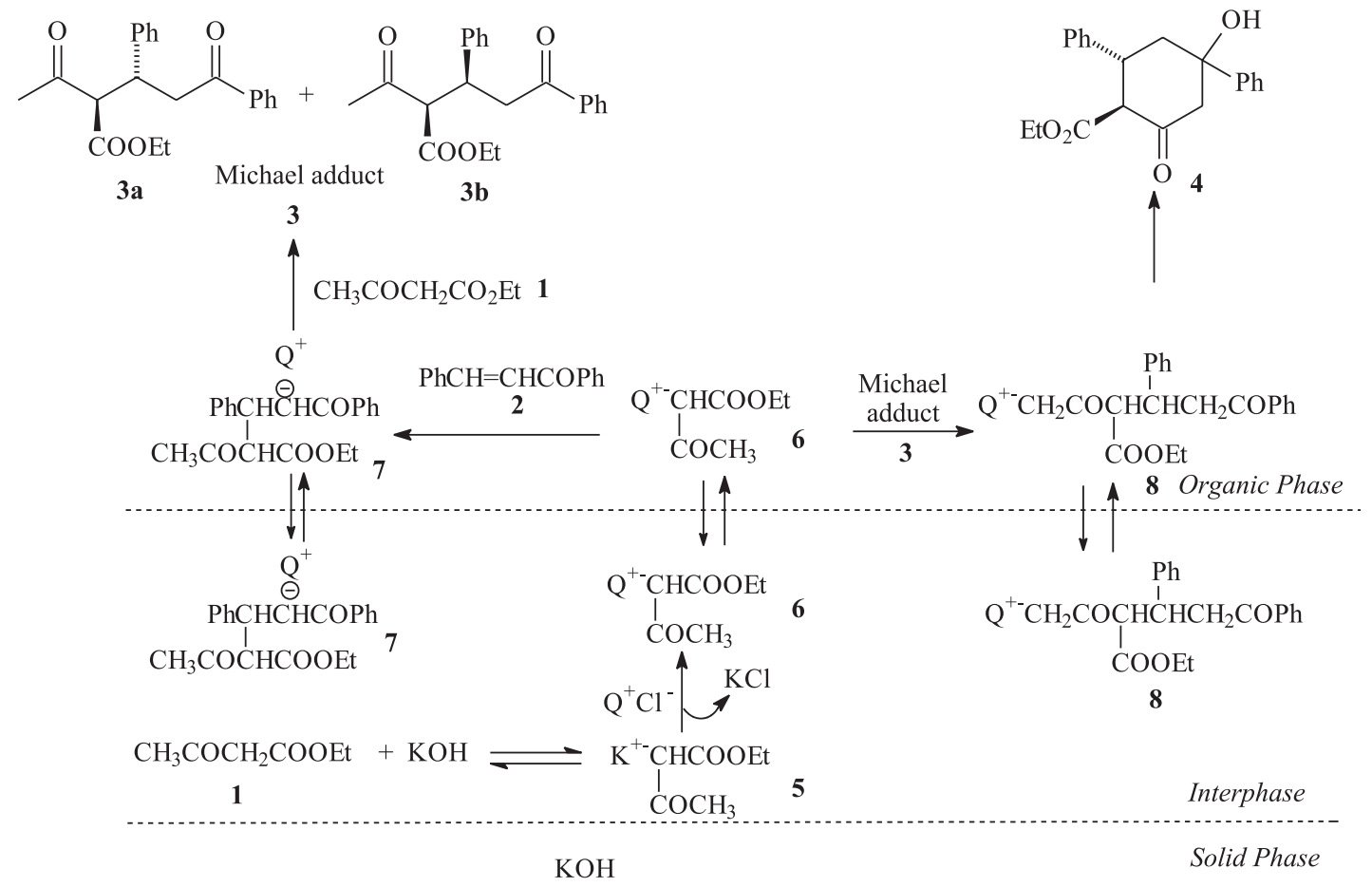

Scheme 2.

The products $\mathbf{3}$ and $\mathbf{4}$ are formed as follow: (i) The acid-base reaction of ethyl acetoacetate $\mathbf{1}$ and hydroxyl ion affords the ionic pair $\mathbf{5}$ ( $\mathrm{K}^{+}$enolate) by an interfacial process; (ii) in the interphase, the quaternary ammonium salt $\left(\mathrm{Q}^{+} \mathrm{Cl}^{-}\right)$promotes an ionic exchange converting 5 into 6, which is transferred to the organic phase; (iii) in the organic phase, the enolate $\mathbf{6}$ reacts with chalcone $\mathbf{2}$ giving the Michael adduct enolate 7; (iv) the Michael adduct enolate 7 removes the acidic hydrogen from ethyl acetoacetate $\mathbf{1}$ producing the Michael adduct $\mathbf{3}$ and forming again the enolate $\mathbf{6} ;(v)$ in the organic phase, the ion pair $\mathbf{6}$ removes the acidic hydrogen from Michael adduct 3 leading to the enolate-adduct $\mathbf{8}$ which undergoes the cyclization process leading to product 4 .

It was observed that for the catalyzed reaction using ratio of donor/acceptor $6: 1$ and temperature of $60{ }^{\circ} \mathrm{C}$, the ratio 3/4 remains very similar $(\sim 1: 3.5$, Table 1 , entries 1 $4)$. On the other hand, at the same conditions but in the absence of catalyst, the proportion of 4 in the ratio $3 / 4$ is higher than the catalyzed reaction $(1: 8.5$, Table 1 , entry $6)$. Thus, the cyclization process seems to be relatively more efficient for the uncatalyzed reaction. This result suggests a transition state in the formation of $\mathbf{4}$ (Figure1) which involves the participation of cations $\mathrm{Q}^{+}$and $\mathrm{K}^{+}$.

The main feature of this proposed transition state is the coordination of two oxygen atoms with the quaternary ammonium cation $\mathrm{Q}^{+}$or $\mathrm{K}^{+}$forming a stable 6-membered ring. Thus, we can propose that chelation is more favorable

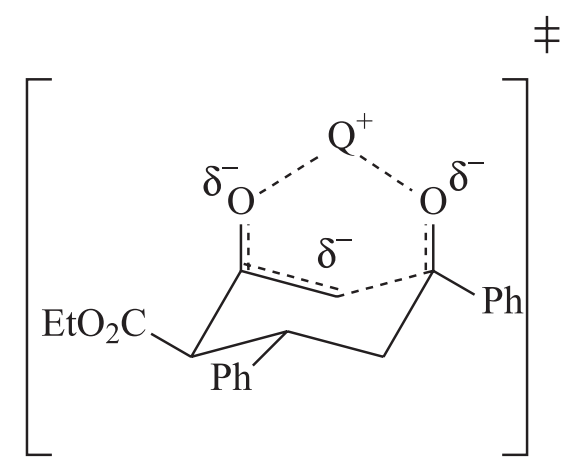

Figure 1. Transition state which leads to cyclic product 4 .

with a small cation as $\mathrm{K}^{+}$as compared to a bulky one, $\mathrm{Q}^{+}$. As a consequence, the annulation process should occur more effectively in the uncatalyzed reaction (Table 1 , entries 4 and 6). On the other hand, it seems reasonable to suggest that the catalyst function in the formation of product 3 seems to be restricted to increase the rates of reaction in the following ways: $(i)$ transference of enolate 6 from an interphase to an organic phase and (ii) reaction of 6 with chalcone 2, culminating in an enhanced global rate of reaction, Scheme 2.

Ratio of donor/acceptor. The analysis of data of Table 1 shows that when the reaction was conducted with excess of donor (entry 4 ), the proportion of cyclic product $\mathbf{4}$ in the ratio 3/4 was lower as compared to reaction using stoichiometric amounts of donor/acceptor (entry 7). A reasonable explanation for this result is based on the 
competition between the donor $\mathbf{1}$ and Michael adduct $\mathbf{3}$ for reaction with the base. The excess of $\mathbf{1}$ in the reaction increases the formation of enolate $\mathbf{6}$ which leads to Michael adduct $\mathbf{3}$, Scheme 2 .

Temperature. At $60{ }^{\circ} \mathrm{C}$, the thermodynamically more stable cyclic product $\mathbf{4}$ is favored. Thus, a higher proportion of 4 in the ratio $\mathbf{3 / 4}$ is obtained when the reaction is conducted under optimal conditions (Table 1, entry 7). In this case, the parameters of ratio of donor/acceptor and temperature seem to act with synergism to produce $\mathbf{4}$ as the major product.

Influence of catalyst structure. Using the optimal conditions to obtain $\mathbf{3}$ plus $\mathbf{4}$ in a maximum global yield, the performance of five ammonium salts as catalysts was compared, Table 2. The highest yields were obtained with the catalysts TEBAC and TBAH (Table 2, entries 1 and 2), followed by Cetrimide ${ }^{\circledR}$ (Table 2, entry 3), Aliquat $^{\circledR 3} 36$ and CBTA (Table 2, entries 5 and 4). These results were interpreted on the basis of the organophilicity and accessibility properties of the ammonium salts.

Table 2. Michael addition of $\mathbf{1}$ to chalcone $\mathbf{2}$ using different tetraalkylammonium salts as catalysts

\begin{tabular}{|c|c|c|c|c|}
\hline Entry & Catalyst & Ratio of $3: 4$ & Total Yield ${ }^{e}$ & $q^{f}$ \\
\hline 1 & TEBAC & $1: 9$ & 99 & 1.64 \\
\hline 2 & $\mathrm{TBAH}^{\mathrm{a}}$ & $1: 3$ & 99 & 1.00 \\
\hline 3 & Cetrimide ${ }^{\circledR} \mathrm{b}$ & $1: 2$ & 89 & 3.06 \\
\hline 4 & $\mathrm{CBTA}^{\mathrm{c}}$ & $2: 1$ & 45 & 0.89 \\
\hline 5 & Aliquat $^{\circledR} 336^{\mathrm{d}}$ & $24: 1$ & 60 & 1.38 \\
\hline
\end{tabular}

atetrabutylammonium hydrogen sulfate; ${ }^{b}$ hexadecyltrimethylammonium bromide; 'benzyltributylammonium chloride; ${ }^{\mathrm{d}}$ methyl-

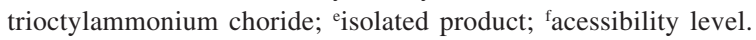

It is well known that the catalyst efficiency increases with increases of the catalyst organophilicity due to high concentration of catalyst in the interphase and organic phase. In this case, the nucleophile is properly transferred from the interphase to the organic phase. On the other hand, an extremely organophilic catalyst exhibits a lower concentration in the interphase. It remains mainly in the organic phase resulting in an inefficient transfer of nucleophile from interphase to organic phase. ${ }^{5}$

The accessibility of catalyst is directly related to an open-faced structure of the quaternary ammonium cation. The nitrogen of a quaternary ammonium cation is considered increasingly acessible as the chains of the quaternary ammonium cation are shorter with particular significance to the shortest alkyl chain. As the alkyl chains of the quaternary ammonium cation decrease in size the charge density on the quaternary cation is higher and the positive charge on the quaternary cation can eletrostatically interact more closely with the nucleophile. A quantitative parameter for characterizing accessibility, termed q, is simply the sum of the reciprocals of the lenght of the linear alkyl chains attached to the central nitrogen of the quaternary ammonium cation: $\mathrm{q}=1 / \mathrm{C} \#_{1}+1 / \mathrm{C} \#_{2}+$ $1 / \mathrm{CH}_{3}+1 / \mathrm{CH}_{4}$, where $\mathrm{C \#}$ is the number of carbon atoms in each of the four alkyl chains in the quaternary cation. ${ }^{5}$ The accessibility values (q) for the catalysts used in this report are summarised in Table 2. Thus, the TEBAC and TBAH containing 13 and 16 carbon atoms, respectively, can be considered catalysts with a reasonable organophilicity and accessibility to promote an efficient transfer of the donorenolate 6 from the interphase to the organic phase, Scheme 2. The catalyst CBTA (19 carbon atoms) exhibits moderate organophilicity but a low accessibility, decreasing the transfer of 6 to organic phase. Although Aliquat ${ }^{\circledR 336}$ (25 carbon atoms) shows a reasonable accessibility, it is extremely organophilic. The Cetrimide ${ }^{\circledR}$ (19 carbon atoms) showed an intermediate efficiency, with a moderate organophilicity and a high acessibility (Table 2, entry 3 ).

As Table 2 shows, the proportion of 4 in the ratio 3/4 decreases as follows: TEBAC (9) $>$ TBAH (3) $>$ Cetrimide $^{\circledR}$ (2). Moreover, in the presence of catalysts CBTA and Aliquat ${ }^{\circledR 336}$, the selectivity has changed to the Michael adduct 3 as the major product in a proportion of 2 and 24, respectively (Table 2, entries 4 and 5). These results can be explained by invoking the 6-membered ring transition state in the formation of cyclic product 4 , Figure 1 . Thus, the tighter the chelation with $\mathrm{Q}^{+}$, the more stable the transition state culminating in a greater quantity of $\mathbf{4}$. In this case, the best catalyst to produce compound $\mathbf{4}$ was TEBAC (Table 2, entry 2). It seems reasonable to suggest that each ethyl group attached to the nitrogen atom is properly short in size to possess an ideal distance separating cation from anion as well as an adequate positive charge density on this central atom ensuring a tight chelation. In addition, a $\pi-\pi$ interaction between the benzyl group of the catalyst and a phenyl group of substrate can provide an extra stabilisation for this transition state, as illustrated in Figure 2.

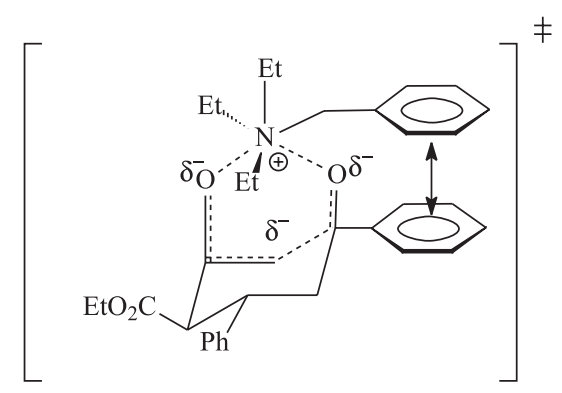

Figure 2. Transition state in the formation of product 4 using TEBAC. The tight chelation with $\mathrm{Q}^{+}$and $\pi-\pi$ interaction between the benzyl group of the catalyst and a phenyl group of substrate. 
For TBAH, the butyl group is greater in size developing lower positive charge density on nitrogen and without any extra stabilisation. Furthermore, it is possible to suggest that the greater length of the butyl groups is responsible for increasing the distance between the cation and the anion decreasing the level of chelation. Likewise, a greater decrease in the proportion of $\mathbf{4}$ when CTAB was used can be attributed to the presence of the long hexadecyl chain. As can be seen, the longer alkyl chain in the quaternary ammonium can provide less positive charge density on the nitrogen and longer distance between the ammonium cation and anion. It culminates in a weak chelation and therefore a more unstable transition state. The three octyl chains in the Aliquat ${ }^{\circledR 3} 36$ seem to be evidence for this proposal. In this case, lower stability of the transition state is responsable for a change in the product distribution where Michael adduct 3 is obtained in the majority (Table 2, entry 5). Finally, the instability of the transition state caused by the use of CBTA (Table 2, entry 4) could be due to the difficulty to promote an efficient chelation related to the size of the butyl chains. In this case, the transition state depicted in Figure 2, which evocates an adequate $\pi-\pi$ interaction between the benzyl group of the catalyst and a phenyl group of the substrate is not favored.

In summary, we have demonstrated that, after variation of the reaction parameters, compounds $\mathbf{3}$ plus $\mathbf{4}$ could be obtained in good yield by Michael addition of ethyl acetoacetate to chalcone via phase transfer catalysis. In addition, based on the stability of a 6-membered cyclic transition state influenced by the structure of ammonium cation, we have devised an explanation for the product distribution in the annulation process.

\section{Experimental}

\section{General}

NMR spectra were recorded on a Bruker DRX 500 spectrometer operating at $500 \mathrm{MHz}$ for proton and 125 $\mathrm{MHz}$ for ${ }^{13} \mathrm{C}$. IR spectra were run on a Perkin-Elmer 1000 FT-IR spectrometer using KBr pellets. Melting points were determined on a Mettler FP5 apparatus and are uncorrected. Gravity column chromatography was performed on Merck Kieselgel 60 (70-230 mesh).

\section{General procedure for the Michael addition of ethyl acetoacetate 1 to chalcone 2}

A mixture of ethyl acetoacetate (23 or $3.8 \mathrm{mmol})$, chalcone $(3.8 \mathrm{mmol}), \mathrm{KOH}(2.3$ or $0.38 \mathrm{mmol})$ and tetraalkylammonium salt (2.3 or $0.38 \mathrm{mmol})$, solvent free, was vigorously stirred by a mechanical stirrer at $60{ }^{\circ} \mathrm{C}$ or room temperature in reaction time that varied from $15 \mathrm{~min}$ to $4 \mathrm{~h}$. The reaction mixture was diluted with chloroform $(30 \mathrm{~mL})$, the organic extract was treated with water, and then dried over anhydrous sodium sulfate. After removal of solvent, under reduced pressure, the crude product was purified by column chromatography using a gradient of polarity with hexane, hexane:acetone 1\%, 2\%, 10\%, 20\% and acetone to yield products $\mathbf{3}$ and $\mathbf{4}$.

Ethyl 2-acetyl-3,5-diphenyl-5-oxopentanoate (3)

IR $(\mathrm{KBr}) v_{\max } / \mathrm{cm}^{-1}: 1735,1712,1685,1657,1451$, 1281, 745, 703; ${ }^{1} \mathrm{H} \mathrm{NMR}\left(500 \mathrm{MHz} / \mathrm{CDCl}_{3}\right)$ major $(3 \mathbf{a}): \delta$ 7.18-7.88 (m,10H), 4.18-4.21 (m,1H), 4.04 (d, J 10.0 Hz, $1 \mathrm{H}), 3.93$ (q, J 7.0 Hz, 2H), 3.41 (dd, $J 16.5,4.8 \mathrm{~Hz}, 1 \mathrm{H})$, 3.34 (dd, $J 16.5,8.5 \mathrm{~Hz}, 1 \mathrm{H}), 2.32$ (s, 3H), 0.99 (t, $J 7.0 \mathrm{~Hz}$, $3 \mathrm{H})$; minor $(\mathbf{3 b}): \delta$ 7.18-7.88 (m,10H), 4.18-4.21 (m,1H), 4.03 (d, J9.0 Hz, 1H), 3.93 (q, J 7.0 Hz, 2H), 3.40-3.55 (m, 2H), 2.03 (s, 3H), 1.27 (t, J 7.1 Hz, 3H); ${ }^{13} \mathrm{C} \mathrm{NMR} \mathrm{(125}$ $\mathrm{MHz} / \mathrm{CDCl}_{3}$ ) major (3a): $\delta$ 202.9, 198.4, 168.5, 141.0, 137.3, 133.5, 128.9, 128.8, 128.6, 128.5, 127.5, 65.9, 61.8, 43.1, 40.1, 30.0, 14.1; minor (3b): $\delta$ 202.2, 198.0, 169.2, $140.9,137.3,135.5,129.0,128.8,128.6,128.5,127.5$, $65.2,62.1,43.3,41.1,30.3,14.5$.

\section{2-Ethoxycarbonyl-3,5-diphenyl-5-hydroxycyclohexanone (4)}

mp. 162.8-166.7 ${ }^{\circ} \mathrm{C}\left[162.0-164.0{ }^{\circ} \mathrm{C}\right]^{6} ; \mathrm{IR}(\mathrm{KBr}) v_{\max } /$ $\mathrm{cm}^{-1}: 3394,1748,1709,1638,1493,1158,750,697 ;{ }^{1} \mathrm{H}$ NMR [500 MHz/(CD $\left.)_{2} \mathrm{CO}\right] \delta 7.22-7.66(\mathrm{~m}, 10 \mathrm{H}), 4.74$ (s,1H), 4.10 (d, J 12.0 Hz, 1H), 3.95-4.07 (m, 2H), 3.32 (d, $J 13.0 \mathrm{~Hz}, 1 \mathrm{H}), 2.70(\mathrm{~m}, 1 \mathrm{H}), 2.60(\mathrm{dd}, J 13.0,3.0 \mathrm{~Hz}, 1 \mathrm{H})$, $2.13(\mathrm{~m}, 1 \mathrm{H}), 1.06(\mathrm{t}, J 7.0 \mathrm{~Hz}, 3 \mathrm{H}) ;{ }^{13} \mathrm{C} \mathrm{NMR}[125 \mathrm{MHz} /$ $\left.\left(\mathrm{CD}_{3}\right)_{2} \mathrm{CO}\right] \delta 204.4,169.6,148.8,143.8,129.4,129.2$, $128.5,127.9,127.7,125.5,63.3,60.8,54.1,46.6,43.4$, 14.5 .

\section{Ackowledgements}

We are grateful to FUNCAP and CNPq/PRONEX for financial support. The authors also thank Dr. James D. McChesney for the English revision of the manuscript.

\section{References}

1. For a review, see: Jung, M. E.; Tetrahedron 1976, 32, 1.

2. Bergmann, E. D.; Ginsburg, D.; Pappo, R.; Org. React. 1959, 10, 179; Perlmutter, P.; Conjugate Addition Reactions in Organic Synthesis, Pergamon Press: Oxford, 1992; Little, R. D.; Masjedizadeh, M. R.; Wallquist, O.; McLoughlin, J. I.; 
Org. React. 1995, 47, 315.

3. Oare, A. D.; Heathcok, C. H. In Topics in Stereochemistry; Eliel, E. L.; Wilen, S. H., eds.; John Wiley \& Sons: New York, 1989, vol. 19, p. 227; House, H. O.; Acc. Chem. Res. 1976, 9 , 59; Hoz, S.; Acta Chem. Scand. 1992, 46, 503; Hoz, S.; Acc. Chem. Res. 1993, 26, 69; Hoz, S.; Gross, Z.; J. Am. Chem. Soc. 1998, 110, 7489; Gross, Z.; Hoz, S.; Tetrahedron Lett. 1991, 32, 5163; Mattos, M. C. de; Marzorati, L.; Quim. Nova 1999, 22, 710.

4. Alvarez-Ibarra, C.; Csáky, G. A.; Maroto, M.; Quiroga, M. L.; J. Org. Chem. 1995, 60, 6700; E. Diez-Barra, E.; de la Hoz, A.; Merino, S.; Sánchez-Verdú, P.; Tetrahedron Lett. 1997, 38, 2359; de la Hoz, A.; Diez-Barra, E.; Langa, F.; Merino, S.; Rodriguez, A.; Sánchez-Verdú, P.; Tetrahedron 1997, 53,
11693; Diez-Barra, E.; de la Hoz, A.; Merino, S.; Rodriguez, A.; Sánchez-Verdú, P.; Tetrahedron 1998, 54, 1835; Kim, D. Y.; Huh, S. C.; Kim, S. M.; Tetrahedron Lett. 2001, 42, 6299; Kim, D. Y.; Huh, S. C.; Tetrahedron 2001, 57, 8933; Lins, F. F. T.; Cunha, L. P. da; Pouliquen, Y. B. M.; Lemos, T. L. G. de; Mattos, M. C. de; Z. Naturforsch. 2004, 59b, 305.

5. Starks, C. M.; Liotta, C. L.; Halpern, M.; Phase-Transfer Catalysis: Fundamentals, Applications and Industrial Perspectives, Chapman \& Hall: New York, 1994.

6. Garcia-Raso, A.; Garcia-Raso, J.; Campaner, B.; Mestres, R.; Sinisterra, J.V.; Synthesis 1982, 12, 1037.

Received: November 19, 2004 Published on the web: August 24, 2005 